\title{
GÊNEROS NÃO-BINÁRIOS: IDENTIDADES, EXPRESSÕES E EDUCAÇ̃̃O
}

\author{
Neilton dos Reis ${ }^{1}$ \\ Raquel Pinho ${ }^{2}$
}

\section{Resumo}

Neste texto, apresentamos um ensaio teórico sobre a construção não-binária de gêneros, no qual destacamos o processo educativo como privilegiado para socialização de adolescentes, jovens e adultos, seja para manutenção, seja para (des)(re)construção de signos e significados que permeiam as identidades. Partimos da problematização das diferenças entre características naturais supostamente pré-discursivas e processo socioculturais para a compreensão de uma estruturação binária na concepção de gênero. Buscamos ainda debater a construção realizada no espaço escolar acerca dos saberes sobre corpos, identidades e socializações. Com isso, propomos uma ação questionadora dos posicionamentos que as escolas têm assumido, de forma a repensar os contornos nos quais a pluralidade identitária pode ser trabalhada.

Palavras-chave: Binarismo de gênero; Socialização escolar; Identidades

\section{INTRODUÇÃO}

Esse trabalho é fruto da inquietação acerca dos processos de construção das identidades e expressões de gênero, bem como seu enlace com o processo de socialização escolar. As identidades dos sujeitos vão se produzindo ao longo da vida, num processo de reprodução de outras já estabelecidas, ou de repulsão. O indivíduo se apropria dos comportamentos de sexo e gênero a ele estabelecidos e os ressignifica interiormente, aceitando ou rejeitando-os. Nesse

\footnotetext{
${ }^{1}$ Mestrando em Educação pela UFJF. Endereço: Rua Lourenço Kelmer, S/N, São Pedro, Juiz de Fora, MG, Brasil, 36036-900. Endereço eletrônico: neilton.dreis@ gmail.com

${ }^{2}$ Doutoranda em Educação pela PUC-Rio. Endereço: Rua Marquês de São Vicente, 225, Gávea, Rio de janeiro, RJ, Brasil, 22451-900. Endereço eletrônico: raquel.aps@ gmail.com
} 
REIS, N.; PINHO, R.

sentido, entendemos a escola como local privilegiado para essa (re)produção, que reforçará ou construirá novos signos e significados às sexualidades e identidades.

\section{CAMINHOS METODOLÓGICOS}

Este artigo foi construído com parte dos dados da pesquisa Diversidade de gêneros $e$ Ensino de Biologia: casos de prazeres e corporeidades não-binários (Neilton DOS REIS, 2015), cuja metodologia consistiu em levantamento bibliográfico e entrevistas semiestruturadas. As entrevistas aconteceram com cinco jovens de 18 a 23 anos de identidades de gênero não-binárias do estado do Rio de Janeiro. O roteiro das entrevistas contou com perguntas sobre o processo de construção de identidades não-binárias, suas possibilidades de expressões e suas trajetórias escolares.

Neste artigo, demos prioridade para o aprofundamento teórico realizado durante a pesquisa (seções 3, 4 e 5) e alguns relatos sobre as experiências e possibilidades de expressões de gênero, em diferentes espaços, incluindo a escola (seção 6).

\section{DESFAZENDO A DICOTOMIA DETERMINISTA}

O percurso histórico do conceito de gênero, na forma nominal que o concebemos hoje, tem suas raízes nas Ciências Sociais, mais especificamente no campo etnográfico da Antropologia. Os estudos feministas publicados por autoras a partir de 1970 trouxeram uma corrente universalista para os estudos de gêneros, ao observarem um padrão de dominação/submissão nas relações entre homens e mulheres em diversas culturas. Suas análises apontaram para uma ocupação de posições inferiores - em diferentes níveis e graus por mulheres das sociedades observadas. De acordo com Rita Segato ${ }^{3}$ (1998, p. 6) importantes autoras, como Gayle Rubin, Sherry Ortner, Nancy Chodorow, Louise Lamphere, Michelle Rosaldo e Rayna Reiter, puderam contribuir para o conceito de gênero com a observação das hierarquias e das interseccionalidades das relações entre homens e mulheres.

\footnotetext{
${ }^{3}$ Assim como Rachel Pulcinoet al. (2014, p. 128), optamos por referenciar autores e autoras com nome e sobrenome e não apenas com sobrenome, como é feito usualmente. Também consideramos que referenciar apenas o sobrenome seja um reforço à ideia de um suposto sujeito neutro, constantemente subentendido como do gênero masculino. Nossa opção é uma forma de evidenciar as mulheres na pesquisa, principalmente no que se refere às lutas de reconhecimento e valorização da identidade feminina.
} 
Em entrevista concedida à Judith Butler em 2003, Gayle Rubin relata suas contribuições à consolidação teórica dos Estudos de Gênero na década de 70. À época, segundo a autora, a comunidade acadêmica percebia a sociedade - e suas relações de dominação/submissão - em uma visão marxista clássica, onde uma reforma operária modificaria todas as estruturas. Entretanto, o movimento do que ficou conhecido como a segunda onda do feminismo aponta criticamente para uma situação particular, uma dominação que se estruturava nas relações de gênero e sexualidade. Segundo a autora "o problema básico era que o marxismo tinha uma compreensão muito precária de sexo e gênero, e tinha limitações intrínsecas como estrutura teórica para o feminismo" (Gayle RUBIN e Judith BUTLER, 2003, p. 5).

Maria Heilborn (2002, p. 76) reforça a importância da crítica feminista dos anos 70 para a constituição conceitual de gênero que foi concebido como "a construção social do sexo e foi produzido com a ideia de discriminar o nível anato-fisiológico da esfera social/cultural. Em outras palavras, essa categoria analítica visa, sobretudo, distinguir a dimensão biológica da social”. Dessa forma, a autora indica que a espécie humana possui indivíduos machos e fêmeas, mas que a qualidade de ser homem e ser mulher vai ser diferenciada pelo contexto sociocultural que o indivíduo se insere.

Cabe aqui, no entanto, trazer uma reflexão sobre a veracidade de um determinismo natural para a ideia de sexo e sobre a dicotomia polarizada entre sexo e gênero. Todas as definições apresentadas demonstram gênero como uma forma de organização social dos sexos, a partir de uma interpretação, variável em função de tempo e cultura, desses. Entretanto, há que se questionar essa descontinuidade radical entre um dado que seria estruturalmente natural (sexo) e outro socialmente construído (gênero), uma vez que o próprio conceito e entendimento de que há um macho e uma fêmea na espécie humana - o próprio saber biológico formulado para explicar a natureza humana - é um dado culturalmente localizado. Quando contestamos essa característica rígida do sexo podemos chegar à dimensão que o sexo é tão cultural quanto o gênero. Judith Butler (2003, p. 34) provoca apontando que "a rigor, talvez o sexo sempre tenha sido o gênero, de tal forma que a distinção entre sexo e gênero revela-se absolutamente nenhuma".

Assim, nesse trabalho, identificamos sexo como dado cultural estabelecido para designar a natureza dos corpos. Como defende Judith Butler (2003, p. 25) um "efeito do aparato de construção cultural que designamos por gênero”. Esse dado, que no senso comum é entendido como algo que antecede ao discurso gênero - que está neutro a ele, aparece aqui desconstruído do que se polarizou como macho e fêmea, entendido como aparato para a 
REIS, N.; PINHO, R.

manutenção binária do gênero. Não entendemos as divergências das combinações cromossômicas XX e XY como patológicas ou afastadas do sistema reprodutivo humano. Ao contrário, acreditamos que o entendimento delas enquanto patologias reforça a normatização, a higienização e a biologização de um sistema binário. Como explica Nádia Pino,

A experiência intersex mostra em níveis extremados a normalização compulsória dos corpos e das identidades, pois evidencia a restrição das identidades de gênero ao binarismo homem-mulher e a das identidades sexuais a uma suposta coerência necessária entre corpo sexuado, práticas e desejos. (Nádia PINO, 2007, p. 152)

Por gênero, devido à complexidade do conceito, vamos compreender a multiplicidade de discursos, produtos de cultura, acerca do que seja ser homem e ser mulher. Por ser discurso, é logicamente impossível localizá-lo num estado pré-discursivo - ou natural - da espécie humana. A identidade de gênero se caracteriza na concepção individual de sou homem, sou mulher ou sou um gênero a parte dessas opções; enquanto que a expressão de gênero é a representação física - incorporada - dessa identificação. Além disso, encaramos o gênero como uma categoria de leitura da sociedade, de maneira a constituir um variante de aspectos práticos observáveis, tais como: diferença salarial, posição social e mesmo ocupação geográfica.

O gênero binário se manifesta quando os corpos são polarizados no binarismo nas diversas áreas e saberes da sociedade. As características secundárias de corpos femininos e corpos masculinos, tais como pelos, seios e quadris, passam a determinar o que é ser homem e ser mulher para cada área. Por exemplo, a mídia vai, através de produções audiovisuais, realçar diferentes características ditas essenciais e específicas para ser homem (como virilidade e racionalidade) e, assim, construir num campo simbólico o que significa efetivamente ser homem. Como aponta Ruth Sabat (2001, p. 16), o currículo cultural (esse conjunto de reforços constituídos e constituidores de relações sociais) "faz parte de uma pedagogia específica, composta por um repertório de significados que, por sua vez, constroem e constituem identidades culturais hegemônicas".

Assim, essas construções não permanecem no campo simbólico, mas extravasam para a materialidade do corpo. Seguindo o exemplo, os homens poderão frequentar a academia para desenvolver massa muscular, pela questão estética, o que daria forma ao simbólico. Essa incorporação reforça a virilidade como característica masculina e auxilia na produção de outras, como a habilidade em certos esportes ou a maior resistência às atividades físicas se 
comparado às mulheres. Assim, todo conhecimento produzido nesses campos simbólicos, através de relações de poder, implica em práticas regulatórias concretizadas no corpo.

\section{EXPECTATIVAS DE GÊNERO}

Uma característica da construção sociocultural dos gêneros que merece atenção é que tal estrutura se apresenta e se constrói de maneira binária, isto é, tendo como possibilidades o masculino e o feminino. Essa forma de construção advém de um suposto determinismo biológico, no qual os corpos são entendidos no dimorfismo macho-fêmea. A esse dimorfismo, como aponta Rita Segato (1998, p. 8), é que são atribuídas as características da matriz masculino-feminino, a partir da "primeira cena" que o indivíduo é apresentado. Tal cena é, tipicamente, a cena familiar onde os papeis de homem e de mulher emergem em performances e traços secundários característicos dessa dualidade.

Nesse sentido o binário de gênero se constitui numa relação oposicional, ou seja, em formato de identidade e alteridade. De acordo com Nadja Hermann (2014, p. 479), a formação de binários oposicionais é uma herança metafísica ocidental, onde a dualidade se constitui entre o eu (identidade) e o outro (alteridade) - sendo este último tudo aquilo que foge do ideal, que ultrapassa o limite da identidade e chega ao estranho. Traduzindo esse conceito para construção binária do gênero, homem e mulher se encontram em posições representadas anatomicamente de maneira estável e socialmente delimitadas em papéis masculinos e papéis femininos. Ser homem implica em não ser mulher, em rejeitar todo e qualquer marcador identitário inscrito no universo feminino.

Rita Segato (1998, p. 4) analisou a relatividade dessas posições através de estudos realizados em conventos e cárceres, chamados instituições totais, ou seja, instituições que têm um regime social e político próprio, restrito ao mundo interior e àqueles que o frequentam. Assim, num convento, por exemplo, onde há apenas mulheres, algumas irão realizar performances ditas masculinas e outras continuarão a cumprir o papel social de mulher ambas recebendo diferentes tratamentos, de acordo com sua performance estabelecida. Vale ressaltar que, nesses casos, ainda que um binário anatômico não exista necessariamente, o social se mantém - produzindo e reproduzindo características da sociedade que está ao redor de determinada instituição total. 
REIS, N.; PINHO, R.

A partir de estudos etnográficos dos papéis sociais desempenhados por homens e mulheres em diferentes épocas e sociedades, constatamos uma relação de dominação e submissão entre os gêneros. Rita Segato (1998, p. 5) indica que não há etnografia que observe uma igualdade de gênero; os estudos da área sempre denunciaram uma estrutura hierarquizada, seja em graus de opressão à mulher, de direitos à liberdade, de oportunidades ou mesmo de sofrimentos. Todas essas observações demonstram que o gênero se apresenta dentro de um domínio de poder, que se revela em diferentes níveis, desde políticas diretas de opressão a sutilezas naturalizadas de dominação. Michel Foucault (1979), em Microfísicas do Poder, apresenta uma discussão em torno da constituição de poder que nos parece observável nos gêneros:

\footnotetext{
Rigorosamente falando, o poder não existe; existem práticas de ou relações de poder. O que significa dizer que o poder é algo que se exerce, que se efetua, que funciona. E tudo funciona como uma maquinaria, como uma máquina social que não está situada em um lugar privilegiado ou exclusivo, mas que se dissemina por toda a estrutura social. Não é um objeto, uma coisa, uma relação. E esse caráter relacional do poder implica que as próprias lutas contra seu exercício não possam ser feitas de fora, de outro lugar, do exterior, pois nada está isento do poder. (Michel FOUCAULT, 1979, p. 16)
}

Sobre esses esquemas de poder, Lorenzo Bernini (2011, p. 20) indica que a construção da identidade sexual dos indivíduos é regrada também por um "sistema binário sexual", no qual os três níveis dessa construção de identidade (sexo, gênero e orientação sexual) são determinados por um jogo de binários. De acordo com o autor, os sujeitos são levados ao enquadramento nos polos sexuais biológicos (macho ou fêmea - tendo por base a constituição genital), nos polos de gênero (papéis sociais de homens ou mulheres) e na orientação sexual (voltando o prazer para o desejo heterossexual). Esses esquemas de poder compõem o que chamamos de matriz heteronormativa ou heteronormatividade. Tal matriz pressupõe relacionamentos sexuais (e românticos) entre os dois polos sexuais biológicos e que estes devem acompanhar os polos de gênero, sendo qualquer relação desviante dessa regra uma aberração - mesmo aqueles indivíduos que não se obrigam às relações sexuais ou românticas, isto é, aqueles que assumem identidades assexuais. Ainda dentro dessa matriz, a relação entre os dois polos se situa em um regime de dominação/submissão - na qual o macho, homem e heterossexual supostamente tem direito de dominação sobre a fêmea, a mulher.

Para Rita Segato (1998, p. 8) e Judith Butler (2003, p. 8), a heteronormatividade é a matriz base para o estabelecimento do poder e da naturalização dos corpos, gêneros e desejos. 
Ela é a primeira inserção do poder na socialização do sujeito e pode ser apresentada como uma grade de símbolos culturais e sociais que se estabelecem de forma cognitiva. Nela, todos os sujeitos são imersos numa repetição ordenada de signos que, como já vimos, começa com aquela primeira cena a que o indivíduo é exposto e continua através de um emaranhado de fatores, como mídia e escolarização e que vão orientar e classificar esses sujeitos de acordo com um ideal comportamental. Esse ideal nunca será plenamente alcançado, mas aquela ou aquele que não fizer a tentativa ou desviar da performance de representação do papel pagará com sua dignidade e estará exposta ou exposto às violências de todo tipo, desde olhares enviesados até linchamentos fatais.

Destacamos também que a caracterização binária do gênero é frequentemente descontextualizada, isto é, encarada como fator único para definir supostas diferenças dicotômicas entre homens e mulheres. O feminino, por exemplo, que nas sociedades em geral ocupam papéis sociais marginalizados, é utilizado como forma de análise isolada; falta um entendimento político-social da estrutura. Ou seja, falta considerar as interseccionalidades de gênero, como classe e etnia, bem como superara ideia de que o gênero se apresenta em polos e passara pensa-lo como um espectro.

De acordo com Lorenzo Bernini (2011, p. 19), toda essa forma binária de ler o gênero tem raízes no determinismo da ciência moderna, na qual variações da estrutura sexual macho ou fêmea eram existências "contranatureza". Para ele, essas existências são estabelecidas como desviantes, como minorias, pois são baseadas em modelos padrões quantitativos, o que ele chama de padrão standard. Ao separar normal e desviante, inclui os "desvios" desse padrão como limite do que é natural. Nas palavras do autor, "as minorias estão na borda da maioria, delimitam a maioria tanto quanto esta as delimita" (Lorenzo BERNINI, 2011, p. 20).

A visão clássica da ciência entendia como "desvios", por exemplo, os indivíduos intersex - antigamente chamados de hermafroditos (Nádia PINO, 2007, p. 151). Independente de classificações, Lorenzo Bernini (2011, p. 20) aponta que a existência desses seres humanos é uma prova de que a natureza de nossa espécie é também transexual. Assim, a natureza sabotaria a estrutura de significantes que impôs sexos binários "verdadeiros". A transexualidade ou, se formos traduzir o termo para aproximá-lo nominalmente de gênero, a transgeneridade, dessa forma, não pode ser encarada como desvio do natural, mas sim desvio da imposição social que se estabeleceu dentro de estruturas maiores de poder. Sobre a noção de transgeneridade na sociedade, Lorenzo Bernini (2011, p. 21) diz que "todo ser humano, se seguisse sua verdadeira natureza, não sentiria apenas desejos sexuais voltados para pessoas de 
REIS, N.; PINHO, R.

sexo masculino ou feminino, mas sentiria também os vestidos sociais seja do homem, seja da mulher, muito apertados".

\begin{abstract}
Mesmo que os sexos pareçam não problematicamente binários em sua morfologia e constituição (ao que será questionado), não há razão para supor que os gêneros também devam permanecer em número de dois. A hipótese de um sistema binário dos gêneros encerra implicitamente a crença numa relação mimética entre gênero e sexo, na qual o gênero reflete o sexo ou é por ele restrito. (Judith BUTLER, 2003, p. 24)
\end{abstract}

Cabe, aqui, explicar o gênero como um espectro, isto é, entende-lo como flutuante na linha entre os polos feminino e masculino - ou mesmo que abandona essa linha (Figura 1). Essas flutuações também são pensadas para as relações afetivas e/ou sexuais dos sujeitos, por vezes também abandonando as delimitações de orientação sexual.

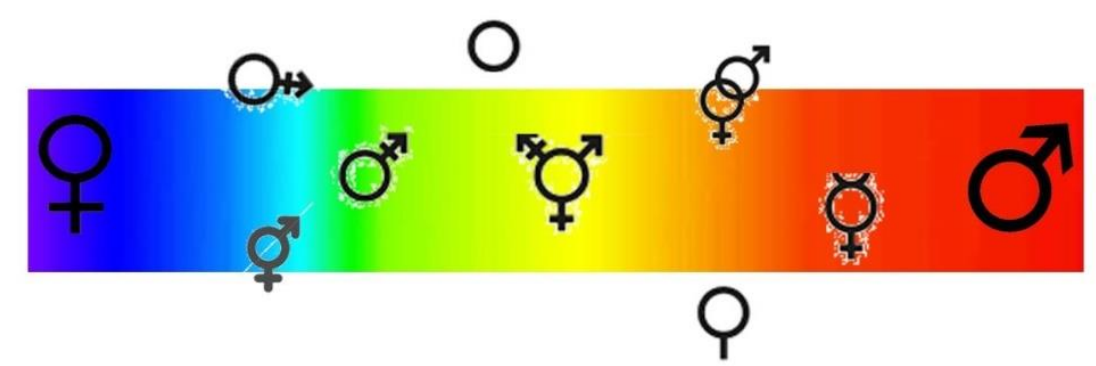

Figura 1: Espectro de gênero. O polo vermelho simboliza o a identidade $100 \%$ feminina e o azul, $100 \%$ masculina. Nas cores do espectro entre os polos e fora da linha se localizam os inúmeros gêneros não-binários - meramente representados por alguns ícones já definidos. (Elaboração própria).

Explorando o conceito de transgeneridade proposto por Lorenzo Bernini (2011, p. 34) como sendo "as pessoas que se identificam com o gênero oposto ao sexo de nascimento", podemos ampliar a compreensão para as pessoas que não se enquadram no gênero determinado a elas no nascimento- ou antes dele, uma vez que durante a gestação já existe uma expectativa em torno da criança quanto ao seu gênero.

Nessa perspectiva, estão também todos os gêneros não-binários que, além de transgredirem à imposição social dada no nascimento, ultrapassam os limites dos polos e se fixam ou fluem em diversos pontos da linha que os liga, ou mesmo se distanciam da mesma. Ou seja, indivíduos que não serão exclusiva e totalmente mulher ou exclusiva e totalmente homem, mas que irão permear em diferentes formas de neutralidade, ambiguidade, multiplicidade, parcialidade, ageneridade, outrogeneridade, fluidez em suas identificações. 
Para exemplificar a multiplicidade das identidades não-binárias de gênero, podemos observar casos como (ESPECTOMETRIA não-binária, 2015):

- bigênero: pessoas que são totalmente de dois gêneros, sem que haja, entretanto, uma mescla bem delimitada entre os dois; qualquer combinação de gêneros é possível, não apenas a combinação feminino com masculino;

- agênero: identidade onde os indivíduos vivenciam ausência de gênero; tem sinônimos como não-gênero ou gendergless;

- demigênero: termo para vários gêneros onde pessoas leem suas identidades como sendo parcialmente femininas ou masculinas e parcialmente alguma identidade não-binária; ou ainda, parcialmente agênero e parcialmente alguma outra identidade não-binária;

- pangênero: identidade que se refere a uma grande gama de gêneros que pode ultrapassar a finitude do que entendemos atualmente sobre gênero; e

- gênero fluido: identidade de pessoas que possuirão o espectro de gêneros em constante mudança, não sendo restrito a dois gêneros apenas.

As expressões dessas identidades exemplificadas serão extremamente variadas, divergindo de indivíduo a indivíduo, bem como de contexto a contexto. Historicamente os gêneros não-binários se aproximaram da população LGBTT $^{4}$ pela luta por equidade de direitos civis e sociais por se enquadrarem socialmente enquanto transgêneros. Tais direitos são alvo de ataques constantes, pois

Em sendo a "identidade" assegurada por conceitos estabilizadores de sexo, gênero e sexualidade, a própria noção de "pessoa" se veria questionada pela emergência cultural daqueles seres cujo gênero é "incoerente" ou "descontínuo", os quais parecem ser pessoas, mas não se conformam às normas de gênero da inteligibilidade cultural pelas quais as pessoas são definidas. (Judith BUTLER, 2003, p. 38).

\section{SOCIALIZAÇÃO ESCOLAR E CONSTRUÇÃO DE IDENTIDADES (BINÁRIAS)}

Para Tomaz da Silva (1999, p. 11) a identidade pode ser entendida como um ato performativo, resultado de construções inacabadas. Nesse sentido, ela é algo mutável, pois dependente de uma leitura de si mesmo em relação a um mundo de significantes que se apresentam instáveis. A identidade apresenta, ainda, conexão com as relações de poder

\footnotetext{
${ }^{4}$ Elegemos a sigla LGBTT para indicar grupos de Lésbicas, Gays, Bissexuais, Travestis e Transexuais. Entendemos que existam muitas combinações desses termos no esforço de representar as diferenças sexuais e de gênero. No entanto, acreditamos que nenhuma combinação dá conta da diversidade de identidades que habitam esses grupos.
} 
estabelecidas na sociedade, seja em nível macro - como os discursos heteronormativos que se instalam em todos os setores sociais, seja em nível micro - de fatos ocorridos "isoladamente" em uma sala de aula, por exemplo.

O processo de construção de identidades está intimamente ligado ao processo de socialização dos indivíduos. O modo como o indivíduo se torna um sujeito social, através dos diferentes espaços sociais que ele poderá se inserir - ou ser inserido -, é determinante na forma com a qual este enxerga o entorno e a si próprio. Maria Heilborn (2002, p. 78) afirma que "isto significa dizer, em última instância, que as escolhas e preferências dos indivíduos são socialmente fabricadas", de modo que escolhas são feitas tendo por base a moral do meio, a qual delimita certas fronteiras entre sujeitos e/ou grupos sociais.

A escola, através de suas diversas práticas, terá forte influência nesse modo como as pessoas se entendem e projetam ações a partir disso. O que se ensina sobre a cultura dos povos indígenas, por exemplo, irá contribuir para a formação de um ideal identitário dessa cultura, o mesmo acontece com as culturas negras e, mais próximo desse trabalho, com os gêneros. Além da construção desse ideal, a escola é um espaço de vivência das identidades, um ensaio do que será aceito e incentivado, ou reprovado e reprimido, pelo "mundo lá fora".

O que fazemos na nossa escola, sem dúvida, interfere na construção da nossa sociedade local, regional e global - e vice-versa. A forma como a ação educativa é pensada e, mais ainda, a forma como se concretiza na sala de aula - e em tantos outros espaços da escola - pode provocar transformações ou (re)produzir uma série de exclusões e desigualdades. (Alexandre BORTOLONI, 2014, p. 132)

Assim como Guacira Louro (2000, p. 13), não tensionamos para a escola todo o poder ou toda a responsabilidade na construção de identidades (de gênero). Outros tantos fatores do chamado currículo cultural geram influências, por vezes até maiores, na constituição do enxergar-se no mundo. A mídia, como apresentado na seção anterior, é um dos fatores mais marcantes do milênio e vários estudos (Ricardo FERREIRA e Amilton CAMARGO, 2001; Ilídio PEREIRA, 2008; Jandira QUEIROZ, 2005) apontam-na como forte responsável pela formação e manutenção de (pre)conceitos. Sobre a representação de sexualidades marginalizadas, Jandira Queiroz (2005, p. 51) afirma que a mídia brasileira

é uma importante fonte de informação sobre o mundo para muitas pessoas, imagens equivocadas ou pouco realistas das minorias sexuais têm um efeito nocivo, já que promovem uma ilusão de que estas pessoas não experienciam alegrias, problemas cotidianos ou emoções humanas. Muitas vezes os jovens brasileiros (e adultos 
também) se espelham em personagens de novelas e a partir disso orientam suas ações. Neste sentido, podemos dizer que as telenovelas são uma ferramenta importante na afirmação de identidades heterossexuais.

Entretanto, é difícil negar a importância das vivências escolares na constituição de ideias, saberes, expectativas e histórias dos sujeitos que por ela passaram. A obrigatoriedade em passar pela Educação Básica e os mecanismos legais para que essa se cumpra indicam uma expectativa social depositada na instituição - e, logo, em suas regras, valores e percepções. E mais, ainda que algum indivíduo não passe - por diversos motivos - pelo ambiente escolar, ele será influenciado por ela quando for cobrado por saberes, posturas e incorporações oriundas dela e adquiridas pelos indivíduos escolarizados.

Guacira Louro (2000, p. 14) infere que as incorporações motivadas pela escola são valorizadas pela sociedade. Um exemplo disso é a prática do silêncio na sala de aula, ou o modo como se sentar e ocupar determinado espaço. $O$ que a autora chama de corpo escolarizado é o corpo impregnado de características, gestos e indicações que foi adestrado para aquele ambiente - e que será testado fora dele. Esse ambiente de "teste" se configura, ainda, como um reforço (ou repressão) das incorporações. Assim, as posturas corporais aprendidas e assumidas na escola poderão ser potencializadas ou rejeitadas pela ação do currículo cultural aliado às outras instituições, como a família e a religião.

É importante explorar que essas construções de identidades acompanhadas de modificações nos corpos são processos constantes e instáveis, estão a todo momento - em diferentes pedagogias - se recompondo. Essa instabilidade é acompanhada, ainda, de pluralidade. Se pensarmos na Educação Básica carioca, por exemplo, vamos encontrar um cenário extremamente variado: seja por disparidades nas diferentes localidades e estruturas escolares, seja por crenças e ideais que variam de agente escolar a agente escolar. Assim, cada construção, ainda que acompanhem generalidades, se constitui como única, complexa e inacabada.

A matriz de gênero definida por Judith Butler (2003, p. 38) terá sua rede estabelecida e reforçada também na escola, através de práticas reguladoras. Nelas, há o estabelecimento de identidades de gênero coerentes com um binário ideal do que seja masculino e feminino. As práticas escolares servirão de reforço ao currículo cultural hegemônico, de forma a legitimar o binário imposto por ele; e tal currículo servirá, em reciprocidade, como reforço ao gênero aprendido na escola. 
REIS, N.; PINHO, R.

A socialização escolar - assim como outros tipos de socialização humana - leva os sujeitos ao desenvolvimento de papéis de gênero de acordo com condições situacionais e com seus corpos e prazeres. As práticas escolares expõem os indivíduos a situações binárias, que favorecem essa matriz - por exemplo, a divisão de fileiras de meninos e meninas para caminharem até a sala de aula. Entretanto, como aponta Rita Radl-Philipp (2014, p. 51), "es especialmente importante tener presente que en el propio proceso primario de socialización y educación es necesario actuar en relación con unos nuevos contenidos identitarios de las personas". Isso porque,

Por meio do processo educativo, a criança apreende signos e significados, atribui valor às suas atitudes e aprende a distinguir os comportamentos socialmente aceitos. Tanto na família quanto na escola, a criança, ao ser reconhecida como um ser existente, passa a se estabelecer como sujeito. Nessas experiências, por meio de reforços positivos e negativos, o indivíduo aprenderá quais são os sinais e os símbolos a serem manejados de forma a ser aceito no contexto sociocultural no qual ele se insere. (Raquel PINHO, 2011, p. 292)

Rita Radl-Philipp (2014, p. 52) reforça essa concepção chamando à atenção outro ponto do processo: o papel das alunas e alunos nas ações educativas. Não podemos entender esses indivíduos como sujeitos passivos que apenas incorporam conceitos rígidos e préestabelecidos. Eles, ao contrário, constituem a socialização escolar ativamente, interferindo na sua dinâmica e dando formatos novos e característicos naquela geração. As atividades desenvolvidas por eles poderão manter padrões antigos sem o questionamento de relações de poder, por exemplo, ou assumir novos significados e significantes. No que concerne ao gênero, as alunas e os alunos reproduzem o esquema binário, mas também podem completá-lo ou ressignificá-lo.

Lorenzo Bernini (2011, p. 20) explora essa ressignificação apontando que gêneros e sexualidades marginalizados têm forçado a entrada no sistema educacional, rompendo com os binarismos. Essas ações abalam o sistema repressivo que impõe uma matriz heteronormativa. Um fator escolar corrente que tem perpassado por toda a discussão de construção de identidades de gênero, políticas educativas e socialização, é a formação e implementação do currículo. De acordo com Helena Altmann (2001, p. 578), o currículo pode servir de análise para as práticas e estratégias educativas que exercem controle sobre os indivíduos e os limita nessa relação de poder do binário de gênero, uma vez que é um dispositivo construtor de ideias e, logo, corpos e sujeitos. 
Alexandre Bortolini (2014) apresenta o currículo como um construtor/reprodutor de conhecimentos que promovem as contradições sociais e, ainda, como fator histórico e culturalmente inserido nessas contradições.

\begin{abstract}
Não é que além de construir conhecimentos, o currículo acaba também produzindo transformações, exclusões ou desigualdades. Ao contrário, transformações, exclusões e desigualdades são produzidas justamente por o que e como ensinamos nas nossas escolas. (Alexandre BORTOLINI, 2014, p. 14, grifos do autor.)
\end{abstract}

A aplicação de políticas públicas a nível nacional em diversidade no que tange à Educação Básica nos últimos anos tem sido lenta e de precária produção e divulgação de materiais de referência. Outras conquistas de estruturação social e direitos civis foram alcançadas, por exemplo, o reconhecimento legal das uniões homoafetivas, o que, direta ou indiretamente, tem modificado as relações dentro do espaço escolar e possibilitado a criticidade da temática tanto por docentes quanto por estudantes.

O conhecimento produzido nas Universidades também tem estimulado uma maior discussão dos gêneros e sexualidades. E, ainda que na área de Ensino de Biologia esteja se iniciando, tem-se percebido a importância das práticas de professores e professoras de Ciências e Biologia na promoção da temática (Felipe BASTOS, 2015).

Pensando de forma específica nas discriminações geradas no espaço escolar pela constituição binária de gênero é importante salientar que as categorias da sexualidade (heterossexual, homossexual e bissexual) também foram idealizadas dentro do binarismo. De forma que uma educação para sexualidades e identidades diversas pode, mesmo atenta às sexualidades divergentes, reforçar uma matriz binária e, por isso, se contradizer. Como isso, percebe-se a importância de uma pedagogia questionadora da constituição das identidades uma vez que essas também são formuladas dentro de uma matriz de gênero.

\title{
6 (RE)EXISTÊNCIAS NÃO-BINÁRIAS
}

Na pesquisa Diversidade de gêneros e Ensino de Biologia: casos de prazeres $e$ corporeidades não-binários (Neilton DOS REIS, 2015), nem todas as pessoas entrevistadas possuem as mesmas interseccionalidades, a mesma concepção da matriz de gênero ou ainda a mesma forma de expressar a não-binaridade. Tal fato era esperado, uma vez que o espectro 
REIS, N.; PINHO, R.

que separa gênero feminino de gênero masculino é extremamente amplo - e ainda maior quando observamos gêneros que não se enquadram nessa linha, como indicado na Figura 1.

Para as pessoas entrevistadas, o processo de identificação com algum gênero nãobinário ocorreu, ainda, de forma gradativa. Em um primeiro momento, todas se identificavam com alguma sexualidade divergente da heterossexualidade, seja gay, lésbica, bissexual. Para depois se conhecer na não-binaridade de gênero.

Os relatos revelam que muitos casos de não-binaridade de gênero podem passar velados durante a Educação Básica, por diferentes fatores que vão da ordem individual - ainda não entender o que está acontecendo com a própria identidade de gênero, à ordem coletiva quando o meio ou instituição social no qual a pessoa está inserida (família, escola, grupos de amigos) geram forte influência e normatização para o binário. É importante notar que esses dois fatores não estão dissociados, as questões de ordem individual serão fortemente afetadas pelas de ordem coletiva, e vice-versa - como indicou Maria Heilborn (2002, p. 78).

Estudante 1: Eu vim para o Rio em 2010 pra fazer engenharia e eu me descobri uma pessoa trans-masculina não-binária em, acho que uns, acho que não tem nem um ano, mais ou menos. Comecei a estudar, pelo feminismo eu descobri a transexualidade $e$ comecei a estudar e me identifiquei bastante. Aí você começa a entrar naquela fase de negação: "Eu não sou trans." Não é uma categoria que você quer estar. Mas aí como as identificações eram muitas e eu acabei me identificando como trans: "Não, eu sou mesmo isso, porque tudo o que as pessoas viveram e tudo o que elas passaram eu me via na história das pessoas".

No trecho acima, percebemos que as identificações acontecem por comparação de histórias de vida. Dessa forma, a socialização se torna peça-chave para um melhor entendimento da própria identidade de gênero e enquadramento social, como apontou Anne Fauto-Sterling (2006, p. 40).

As formas de identificação e expressão são, por vezes, também formas de resistências e combate a uma matriz na qual essas pessoas não estão contempladas - ou pior, que lhe causam violências. A problematização vai além quando ocorre o rompimento dentro de um dos polos do binário. Há, no entanto, quaisquer complicações quando algumas expressões de gênero são idealizadas visando a desconstrução de um polo do binário. A utilização de acessórios e vestimentas socialmente construídos enquanto femininos por homens pode caminhar em dois objetivos: o primeiro, como forma de resistência, de transmitir que homens podem sim usar saias, batons ou espartilhos, já que esses são objetos comuns; o segundo, num 
sentido de aproximação com o outro polo, uma vez que espartilhos são construídos socialmente como femininos, um homem pode utilizá-los para expressar uma identidade de aproximação com o polo feminino. As duas formas por vezes se confundem e podem anular a outra.

Estudante 2: E eu não acho necessário ficar explicando como eu me sinto em tal momento. Porque, não sei, ainda sou meio confusa quanto à isso tudo. Porque é complicado você explicar como eu me sinto dentro da não-binaridade. Não vão ser coisas binárias que vão significar como eu me sinto, sabe?! Me sinto, tipo: "sabe um homem..." não é desse jeito. Não é: "como uma mulher..." não é. Então, é complicado. Eu acho estranho.

Estando também a linguagem resumida a uma significação binária em torno da matriz de gênero, também ela assume formas binárias de expressão - seja nas construções sociais em torno da linguagem corporal, seja na construção da língua portuguesa que prevê adjetivos e substantivos femininos ou masculinos. Assim, como utilizar uma estrutura da matriz binária para explicar a não-binaridade? Faltam palavras. Sem contar a dificuldade de construir palavras para não-binários dentro de um sistema binário. Poderia dizer que falta sistema. Essas complicações se agravam ao ponto de se banalizar a não-binaridade por não se compreender quaisquer termos próprios, questionando mesmo a existência dessas identidades de gênero.

Estudante 1: Ninguém tem conhecimento e se tem as pessoas não querem falar, porque é um assunto sujo, um assunto que denigre seu caráter, sei lá o que, um assunto que as pessoas não querem tratar, então se falar de homossexualidade, homossexualismo nas escolas já era um tabu há 10 anos atrás, agora então falar de transexualidade então, eu acho que nem meus professores para falar a verdade nem conheciam sobre.

$\mathrm{O}$ assunto sujo, que mancha o caráter docente e impregna a escola com temáticas intratáveis é visto por estudantes como mal abordados, quando são abordados. Tais estudantes, assim como todos e todas as outras, se formaram numa matriz binária, que foi desconstruída posteriormente pelo contato com vias alternativas de conhecimento.

O espaço escolar, em diversos casos, se demonstra binário e heteronormativo quando deixa de incluir sujeitos que divergem da heterossexual. Assim, os apontamentos apresentados por Jandira Queiroz (2005, p. 51) quanto à necessidade de representatividade no 
REIS, N.; PINHO, R.

espaço escolar entram em dissonância com a realidade vivida por sujeitos. A nãorepresentatividade pode acarretar situações diversas na socialização e na própria construção da identidade: não se entender enquanto um sujeito com particularidades e sociabilidades, alegrias e tristezas, sonhos e frustrações. Em outras palavras, a falta de representatividade torna os sujeitos nulos, sem expectativas futuras.

Em alguns casos, a inclusão e a representatividade aparecem quando encontram pares parecidos ou dispostos ao diálogo. Nesse momento, o colégio assume uma nova configuração, muito mais acolhedor e atrativo. Isso corrobora como estudantes não são meros sujeitos passivos, sem interação e que estão simplesmente à espera de informações para serem testados futuramente. A escola potencializadora da exclusão pode também ser a agente da inclusão. Que escola queremos?

\title{
7 CONSIDERAÇÕES FINAIS
}

A partir de tudo isso, a falta de representatividade das identidades de gênero e sexualidades divergentes da heteronormatividade nos parece clara e inegável, bem como a importância de estudantes que buscam romper com esses silenciamentos provocados por visões normatizadoras da Educação Básica. Como apontam estudos anteriores (Raquel PINHO, 2011, p. 292), os signos e significados regrados pela escola vão influenciar na constituição dos sujeitos sociais. Dessa forma, indicamos a necessidade de mudança no que todas as instâncias reguladoras do processo educativo entendem por sexualidade, identidade de gênero, corpo e papeis de estudantes e docentes. Uma mudança que pautada na valorização da diversidade e nas possibilidades de existência.

\section{NON-BINARY GENDER: IDENTITIES, EXPRESSIONS AND EDUCATION}

\begin{abstract}
In this text is introduced a theoretical essay about the non-binary construction of genders, in which it is highlight the educational process as privileged to socialization of adolescents, youth and adults, either for maintenance or for (des)(re)construction of signs and meanings that permeate the identities. This study starts from questioning the differences between natural
\end{abstract}


characteristics, supposedly pre-discursive, and socio-cultural process for understanding a binary structure on gender conception. In addition, it would like to pay attention in the constructions carried out at school about the knowledge of bodies, identities and socialisation. Thus, it is propose a questioning action of positions that schools has been taken in order to rethink the contours in which the plurality identity can be worked.

Keywords: Gender Binary; School Socialization; Identities

\section{NO BINARIO DE GÉNERO: LAS IDENTIDADES, LAS EXPRESIONES Y LA EDUCACIÓN}

\section{Resumen}

Este artículo se presenta un ensayo teórico sobre la construcción no binario de géneros, en la que se destaca el proceso educativo como el privilegio de la socialización de los adolescentes, jóvenes y adultos, ya sea para mantenimiento o para (de)(re)construcción de signos y significados que impregnan las identidades. Partimos del cuestionamiento de las diferencias entre las características naturales supuestamente pre-discursivas y los procesos socioculturales para la comprensión de una estructura binaria en la concepción de género. También buscamos discutir la construcción realizada en la escuela sobre el conocimiento de los cuerpos, identidades y socialización. Por lo tanto, se propone una acción de cuestionamiento de las posiciones que las escuelas han tomado con el fin de replantear los contornos en los que la identidad pluralidad puede ser diseñado.

Palabras clave: Binario de género; Socialización escuela; Identidades

\section{REFERÊNCIAS:}

ALTMANN, Helena. Orientação sexual nos parâmetros curriculares nacionais. Revista Estudos Feministas, v. 9, p. 575-585, 2001. Disponível em:

$<$ http://www.scielo.br/scielo.php?script=sci_arttext\&pid=S0104026X2

001000200014\&nrm=iso>. Acesso em: 05 de agosto de 2015. 
REIS, N.; PINHO, R.

BASTOS, Felipe. "A diretora sabe que você está trabalhando isso na sala de aula?": Diversidade sexual e ensino de ciências. Dissertação. 180p. Pontifícia Universidade Católica do Rio de Janeiro, Departamento de Educação. 2015.

BERNINI, Lorenzo. Macho e fêmea Deus os criou!? A sabotagem transmodernista do sistema binário sexual. Bagoas - Estudos gays: gêneros e sexualidades. Natal. v. 5, n. 06, 2012. ISSN 2316-6185.

BORTOLINI, Alexandre. O currículo não é. O currículo acontece.IN: BICALHO, Pedro; CIDADE, Maria; CUNHA, Thiago; MATOS, Alfredo. Gênero e Diversidade na Escola: práticas transversais, polifônicas, compartilhadas, inquietas.2014. 143p. Pró-Reitoria de Extensão, UFRJ, Rio de Janeiro.

BUTLER, Judith. Problemas de gênero: feminismo e subversão da identidade. 236p. Rio de Janeiro: Editora Record, 2003.

DA SILVA, Tomaz. Documentos de identidade: uma introdução às teorias do currículo. Belo Horizonte: Autêntica Editora, 1999. ISBN 8586583448.

DOS REIS, Neilton. Diversidade de gêneros e Ensino de Biologia: casos de prazeres e corporeidade não-binários. Monografia. 105p. Universidade Federal Rural do Rio de Janeiro, Curso de Licenciatura em Ciências Biológicas. 2015.

ESPECTROMETRIA NÃO-BINÁRIA. Disponível em: <http://espectrometria-nao-bi naria.tumblr.com/>. Acesso em: 18 de Mar. 2015.

FAUSTO-STERLING, Anne. Cuerpos sexuados: la política de género y la construcción de la sexualidad. Barcelona: Melusina. 526p. 2006.

FERREIRA, Ricardo; CAMARGO, Amilton. A naturalização do preconceito na formação da identidade do afro-descendente. EccoS Revista Científica. São Paulo. v. 3, n. 1, junho, 2001, pp. 75-92

FOUCAULT, Michel. Microfísica do poder. (Organização e tradução de Roberto Machado). Rio de Janeiro: Edições Graal. 1979.

HEILBORN, Maria. Fronteiras simbólicas: gênero, corpo e sexualidade. Cadernos Cepia. Rio de Janeiro.v. 5, p. 73-92, 2002.

HERMANN, Nádia. A questão do outro e o diálogo. Revista Brasileira de Educação. Rio de Janeiro. v. 19, n. 57, 2014.

LOURO, Guacira (Org.).O corpo educado: Pedagogias da sexualidade. Traduções: Tomaz Tadeu da Silva. $2^{a}$ ed. 127p. Belo Horizonte: Autêntica, 2000.

PINHO, Raquel. Corpo, sexualidade e diferença: um ensaio sobre a convivência escolar. Revista Contrapontos. Itajaí. v. 11, n. 3, p. 288-298, 2011. ISSN 1984-7114. 
PINO, Nádia. A teoria queer e os intersex: experiências invisíveis de corpos des-feitos. Cadernos Pagu. Campinas. v. 28, p. 149-174, 2007.

PEREIRA, Ilídio. O discurso midiático e a produção de identidade social. IN: III Seminário Internacional Organizações e sociedade. PUCRS, 2008.

QUEIROZ, Jandira. Rumo ao final do arco-iris: O que mudou no discurso sobre personagens homossexuais na grande midia de entretenimento na ultima década e por que? 66p. 2005. Trabalho de Conclusão de Curso. Centro Universitário de Brasília.

RADL-PHILIPP, Rita. Educación y socialización humana, identidades y nuevos roles de género femenino y masculino: el género a debate. Em Aberto. Brasília. v. 27, n. 92, p. 1-212, 2014.

RUBIN, G.; BUTLER, J. “Tráfico sexual: entrevista”. Cadernos Pagu. Campinas, n. 21, 2003. Disponível em: http://www.scielo.br/scielo.php?script=sci_arttext\&pid=S0104$83332003000200008 \& \operatorname{lng}=$ en \&nrm=iso. Acesso em: 15 de Out. 2015.

SABAT, Ruth. Pedagogia cultural, gênero e sexualidade. Estudos Feministas. Santa Catarina. n. 09. 2001.

SEGATO, Rita. Os percursos do gênero na antropologia e para além dela. Série Antropologia. 22p. Brasília: Departamento de Antropologia, Universidade de Brasília, 1998.

Data de recebimento: 01/02/2016

Data de aceite: 01/03/2016 